\title{
Factors Influencing Work Interference in Patients With Chronic Low Back Pain: A Residency Research Network of Texas (RRNeT) Study
}

\author{
Richard A. Young, MD, Terrell Benold, MD, John Whitham, DO, \\ and Sandra Burge, $\mathrm{PhD}$
}

Introduction: Chronic low back pain (CLBP) is a disabling and expensive condition commonly seen in family physicians' offices. A complete understanding of factors contributing to patients' return to work remains elusive.

Objective: To describe patients with CLBP seen in family physicians' offices and to explore factors interfering with return to work.

Subjects: Three hundred sixty outpatients with CLBP for more than 3 months.

Setting: Ten participating family physicians' offices of the Residency Research Network of Texas.

Primary Outcome: The effect of pain on work effect as measured by a Likert scale.

Results: Patients were typically female (72\%), overweight or obese (mean body mass index, 33.4 ), had pain for many years (mean, 13.6 years), and screened positive for recent depressive symptoms $(83 \%)$. The majority of patients took at least some opioid medication for their pain (59\%). Multivariate linear regression analysis found that the largest single contributor to effect on work was the subjects' score on the SF-36 physical function scale $(\beta=-0.382)$. Other contributors included average daily pain $(\beta=0.189)$, the frequency of flare-ups of pain $(\beta=0.108)$, the effect of the painful flare-ups $(\beta=0.170)$, and current depressive symptoms $(\beta=0.131)\left(\right.$ adjusted $R^{2}$ for model $\left.=0.535\right)$. Age, sex, race/ethnicity, total time the patient has had CLBP, other comorbidities (including a diagnosis of depression), disability status, use of opioids, history of intimate partner violence, social support, and procedures attempted were not predictive.

Discussion: Future studies attempting to demonstrate the effectiveness of interventions in CLBP should measure depressive symptoms and the magnitude and effect of painful flare-ups, not just the overall pain score. The majority of CLBP patients seen in these practices take opioids for their pain. Screening and treating for depression may be reasonable for some patients, though evidence of its effectiveness is lacking. (J Am Board Fam Med 2011;24:503-510.)

Keywords: Analgesics, Depression, Low Back Pain, Occupational Medicine, Practice-based Research

Low back pain is one of the top 10 reasons people seek care from a family physician. ${ }^{1,2}$ The prevalence in the population varies from $8 \%$ to $37 \%$. Back pain is a leading cause of lost work time and disability and

This article was externally peer reviewed.

Submitted 16 December 2010; revised 8 February 2011; accepted 14 February 2011.

From John Peter Smith Hospital FMRP (RAY), Fort Worth, TX; Austin Academic Family Medicine (TB), Austin, TX; Naval Air Station (JW), Corpus Christi, TX; and the Department Family Medicine, University of Texas Health Science Center-San Antonio (SB), San Antonio, TX.

Funding: This study was funded by the Texas Academy of Family Physicians Foundation and the Office of the Medical Dean of the University of Texas Health Science Center at San Antonio. accounts for approximately $23 \%$ of Workers' Compensation payments. ${ }^{1}$ The condition is expensive to the health care system, with diagnosis and treatment of all spine problems estimated to cost $\$ 86$ billion in the United States annually. ${ }^{2}$ Most back pain is temporary and improves in the first few weeks after injury. However, after 3 months of pain or disability, relapse is likely, ${ }^{3}$ and recovery is slow, influenced by many factors including depression, sex, and racial/eth-

Conflict of interest: none.

Corresponding author: Richard A. Young, MD, John Peter Smith Hospital FMRP, 1500 S. Main, Fort Worth, TX 76104 (E-mail: ryoung01@jpshealth.org). 
nic background. ${ }^{1,4}$ Psychosocial factors have been shown to be more predictive of return-to-work status than physical or biomechanical measures. ${ }^{5}$

Many studies have examined predictors of return to work in patients with acute low back pain. ${ }^{6-15}$ Fewer have examined the natural history of chronic low back pain (CLBP), especially in a primary care setting, ${ }^{16,17}$ even though patients seek care for low back pain more commonly from family physicians than other caregivers. ${ }^{18,19}$

Studies of CLBP in other settings have examined the interaction between physical and psychosocial variables, generally recognizing the importance of psychosocial influences on functionality. ${ }^{5,20-22}$ These studies only measured pain as a single variable and did not measure other salient features of CLBP. Intimate partner violence has also been associated with chronic pain, depression, and reduced employment in previous studies. $^{23-25}$

The first purpose of this study was to describe the patients with CLBP seen in family physicians' offices. The second purpose was to determine which combination of physical and psychosocial factors had the greatest influence on the way the CLBP affected the ability to work. In particular, we wanted to know if other features of the CLBP other than a global pain score were independent predictors of work interference.

\section{Methods}

This was a prospective cohort study of CLBP in family medicine patients, though this paper only includes data from the baseline year of enrollment. This study was conducted in outpatient clinics of the Residency Research Network of Texas (RRNeT), a collaboration of 10 ACGME-accredited family medicine residency programs located in Austin, Corpus Christi, Dallas, Fort Worth, Garland, Harlingen, Houston, Lubbock, McAllen, and San Antonio (two programs). Subjects were enrolled from the resident/faculty continuity clinic associated with each residency. These clinics had an average of 29 residents and 10 faculty seeing patients (range, 18 to 72 residents and 7 to 27 faculty), an average of 29,000 patient visits per year (range, 14,000 to 63,000 ), and were all in an urban setting caring for a predominately vulnerable, minority, low-income patient population.

\section{Subjects}

From each clinic, we identified up to 66 consecutive eligible patients with CLBP (mean, 36; range, 9 to 66). Medical student research assistants reviewed clinic ledgers and charts each morning to identify appointed patients who met study criteria. The inclusion criteria were adults age 18 years or over, a diagnosis of CLBP (in general or a specific cause such as stenosis), symptom duration of 3 months or longer, and the subject had two or more visits to this clinic in the previous 24 months. The exclusion criteria were: patients treated for cancer pain and women who were pregnant at intake.

\section{Procedure}

As patients arrived for routine visits with their family physician, student research assistants approached them in the waiting room, the vital signs recording room, or the examination room. Research assistants briefly described the purpose of the study, and invited interested patients into a private room (usually the examination room). Students provided the patient with a consent form, described the study aims and procedures in detail, reviewed the risks and benefits of the study, and provided investigator contact information. Consent forms and survey instruments were available in English and Spanish. After the patient's visit with the family physician, the student retrieved the patient's medical record and abstracted study information from it. Patients received no compensation for their participation.

\section{Measurement}

The survey assessed demographic characteristics, pain severity (10-point scale), frequency and duration of pain episodes (four questions on a Likert scale), physical functioning and general health status (from the MOS-36), ${ }^{26}$ social support and stress (from the Duke Social Support and Stress Scale), ${ }^{27}$ anxiety (from the Beck Anxiety Inventory), ${ }^{28}$ depression (from the PHQ-2), ${ }^{29}$ alcohol and drug use, adverse childhood experiences (from the ACE, abbreviated), and family violence (from the Brief Conflict Tactic Scale). ${ }^{30}$ The chart review was retrospective in nature and included cause and duration of pain, treatments for pain, length of doctorpatient relationship, comorbidities, body mass index (BMI), and insurance status. 
Table 1. Characteristics of Enrolled Patients

\begin{tabular}{|c|c|}
\hline Characteristic & Result, $\mathrm{N}=360$ \\
\hline Female, No. (\%) & $260(72.2)$ \\
\hline Age, mean (SD) & $53.0(13.5)$ \\
\hline $\mathrm{BMI}(\mathrm{SD})$ & $33.4(9.1)$ \\
\hline \multicolumn{2}{|l|}{ Race/ethnicity, No. (\%) } \\
\hline Caucasian & $154(44.6)$ \\
\hline Hispanic & $104(30.1)$ \\
\hline African-American & $83(24.1)$ \\
\hline Other & $4(1.2)$ \\
\hline \multicolumn{2}{|l|}{ Education, No. (\%) } \\
\hline Less than high school & $71(19.9)$ \\
\hline High school or GED & $120(33.7)$ \\
\hline Some college or technical & $121(34.0)$ \\
\hline College or postgrad & $44(12.4)$ \\
\hline Employed currently, No. (\%) & $81(22.9)$ \\
\hline $\begin{array}{l}\text { On disability or applying for } \\
\text { disability, No. }(\%)\end{array}$ & $177(49.2)$ \\
\hline \multicolumn{2}{|l|}{ Household income, No. (\%) } \\
\hline$<\$ 1000$ per month & $166(50.9)$ \\
\hline$\$ 1000$ to $\$ 1999$ per month & $82(25.2)$ \\
\hline$\$ 2000$ to $\$ 2999$ per month & $32(9.8)$ \\
\hline$\$ 3000$ or greater & $46(14.1)$ \\
\hline \multicolumn{2}{|l|}{ Comorbidities, No. (\%) } \\
\hline Osteoarthritis (other than back) & $55(15.3)$ \\
\hline Asthma & $57(15.8)$ \\
\hline COPD & $47(13.1)$ \\
\hline Diabetes & $91(25.3)$ \\
\hline Depression or anxiety & $152(42.2)$ \\
\hline GI disorders & $84(23.3)$ \\
\hline Heart disease & $34(9.4)$ \\
\hline Hypertension & $197(54.7)$ \\
\hline High cholesterol & $115(31.9)$ \\
\hline Takes opioid medication, No. (\%) & $210(58.5)$ \\
\hline $\begin{array}{l}\text { Takes daily scheduled opioid } \\
\text { medications, No. (\%) }\end{array}$ & $94(26.1)$ \\
\hline \multicolumn{2}{|l|}{$\begin{array}{l}\text { Other treatments in the previous } \\
12 \text { months }\end{array}$} \\
\hline Acupuncture & $15(4.2)$ \\
\hline Chiropractor or adjustments & $38(10.6)$ \\
\hline Ice/heat & $184(51.1)$ \\
\hline Massage & $100(27.8)$ \\
\hline Pain clinic & $66(18.3)$ \\
\hline Physical therapy & $89(24.7)$ \\
\hline Injections & $60(16.7)$ \\
\hline Surgery & $17(4.7)$ \\
\hline Yoga & $9(2.5)$ \\
\hline \multicolumn{2}{|l|}{$\begin{array}{c}\text { In general, would you say your } \\
\text { health is. . ? No. (\%) }\end{array}$} \\
\hline Excellent & $10(2.8)$ \\
\hline Very good & $37(10.5)$ \\
\hline \multirow[t]{2}{*}{ Good } & $81(22.9)$ \\
\hline & Continues \\
\hline
\end{tabular}

Table 1. Continued

\begin{tabular}{lc}
\hline Characteristic & Result, $\mathrm{N}=360$ \\
\hline Fair & $137(38.7)$ \\
Poor & $89(25.1)$ \\
PHQ-2 score (depressive & \\
$\quad$ symptoms in the last 30 & \\
days), ${ }^{*}$ No. (SD) & \\
2 & $61(17.3)$ \\
3 to 4 & $91(25.8)$ \\
5 to 6 & $109(30.9)$ \\
7 to 8 & $92(26.0)$ \\
Intimate partner violence, No. & \\
$\quad$ (\%) $\dagger$ & \\
Ever & $90(36.1)$ \\
In past 12 months & $12(4.8)$ \\
In past 30 days & $10(4.0)$ \\
Sum of supportive people checked & $2.6(1.8)$ \\
$\quad$ (range, 1 to 9), (SD) & \\
Patient has a written pain & $67(18.6)$ \\
$\quad$ contract, No. (\%) & \\
\hline
\end{tabular}

*Positive screen is any score $>2$.

$\dagger \mathrm{N}=249$ because these questions were only asked in 2008 .

BMI, body mass index; COPD, chronic obstructive pulmonary disease; GI, gastrointestinal; PHQ-2, Patient Health Questionnaire.

\section{Analysis}

This analysis used only the baseline data from this study. Results were first analyzed by descriptive statistics. Bivariate and then multivariate linear regression analyzed the relationship between contributing factors and the impact of the CLBP on the patient's ability to work. The dependent variable, pain effect on work, was defined as the answer to: "How much does pain interfere with your normal work (including both house work and paid work)?" All variables were tested for significance using backwards elimination by major variable subsets. Variables from the bivariate analyses were included in the multivariate model if their $P$ value was $<0.2$.

Interaction terms between each other pain variable (such as duration of pain, average pain score in last 30 days, and others) and other key remaining variables were tested in models with the dependent variable. A tolerance of less than 0.1 or a variance inflation factor (VIF) greater than 10 were used to define a significant interaction term. Additional analyses were performed, stratified by variables found to have significant interactions. Final models were checked for significant colinearity between the variables. The statistical software used was SPSS 17 (SPSS, Inc., Chicago, IL). 


\section{Results}

Characteristics for the 360 recruited patients are reported in Table 1 . An additional 16 subjects enrolled but did not have data on either the chart review or survey, and 53 subjects declined to participate for a variety of reasons. This was a middleaged, predominantly female (72\%) sample with a wide range of ages (18 to 89 years). Recruited patients were typically obese (average BMI, 33.4), had multiple comorbidities, did not complete education beyond high school (54\%), had low incomes (51\% less than $\$ 1000 /$ month), were not employed (77\%), had back pain for a mean of 13.6 years, reported their health as fair or poor $(64 \%)$, and screened positive for depressive symptoms in the previous 30 days $(83 \%)$, though a minority had a documented diagnosis of depression or anxiety $(42 \%)$. More than half the population took some form of opioid medication, based on the chart review $(59 \%)$, and a minority was on a written pain contract (an agreement between doctor and patient on medication adherence, clinic visits, and testing expectations, and consequences if expectations were not met: (19\%).

\section{Pain Variables}

Patients reported significant daily pain (6.8 on a 10 -point scale) (Table 2). The majority reported experiencing pain every day $(66 \%)$, with the pain most commonly lasting several hours or less (54\%). The vast majority of patients reported flare-ups of their pain in the previous 12 months $(96 \%)$ that had a major impact on their life $36 \%$ could not work, $21 \%$ were bed-bound, and 19\% were dependent on others to feed, clothe, and bathe them during a flare-up).

Bivariate analysis showed significant correlation between most pain variables and the dependent variable, pain effect on work, except duration of pain and the length of time an episode of pain lasts. Age, sex, education, and most comorbidities were not significantly correlated with pain effect on work, except chronic obstructive pulmonary disease and depression.

Multivariate linear regression results examining predictors of pain effect on work are shown in Table 3. Significant independent predictors included both the measure of average daily pain as well as two measures of the effect of pain flare-ups. Recent depressive symptoms as measured by a pos-
Table 2. Pain Variables

\begin{tabular}{|c|c|}
\hline Pain Effect & Result, $\mathrm{N}=360$ \\
\hline Average pain level* (SD) & $6.8(2.2)$ \\
\hline Worst pain level* (SD) & $8.7(5.3)$ \\
\hline Duration of pain, years (SD) & $13.6(13.1)$ \\
\hline \multicolumn{2}{|c|}{$\begin{array}{c}\text { How often did you have back pain in the } \\
\text { last } 30 \text { days? No. (\%) }\end{array}$} \\
\hline Never & $2(0.6)$ \\
\hline Once or twice & $18(5.0)$ \\
\hline Several times per week & $101(28.0)$ \\
\hline Every day & $239(66.4)$ \\
\hline \multicolumn{2}{|c|}{$\begin{array}{l}\text { When you had pain in your back, how } \\
\text { long did it last? No. (\%) }\end{array}$} \\
\hline No pain & $2(0.6)$ \\
\hline Less than 60 minutes & $40(11.2)$ \\
\hline Two to several hours & $151(42.3)$ \\
\hline All day and night & $111(31.1)$ \\
\hline Days & $53(14.8)$ \\
\hline \multicolumn{2}{|c|}{$\begin{array}{l}\text { In the past } 12 \text { months, how often did you } \\
\text { have a flare-up in your back pain, } \\
\text { when it got extra painful? } \\
\text { No. }(\%)\end{array}$} \\
\hline Never & $15(4.2)$ \\
\hline 1 to 5 times & $69(19.3)$ \\
\hline 6 to 9 times & $57(16.0)$ \\
\hline $10+$ times & $129(36.2)$ \\
\hline Constant and severe pain & $86(24.2)$ \\
\hline \multicolumn{2}{|c|}{$\begin{array}{l}\text { When your back pain flared up in the } \\
\text { past } 12 \text { months (got extra painful), } \\
\text { how did it affect your life? } \\
\text { No. }(\%)\end{array}$} \\
\hline Little effect & $19(5.4)$ \\
\hline Limited usual work & $70(25.3)$ \\
\hline Could not do work & $125(35.5)$ \\
\hline Could not move from bed & $72(20.5)$ \\
\hline Dependent on others & $66(18.8)$ \\
\hline \multicolumn{2}{|c|}{$\begin{array}{l}\text { How much does pain interfere with your } \\
\text { normal work (including both } \\
\text { housework and paid work)? } \\
\text { No. (\%) }\end{array}$} \\
\hline No effect & $14(4.0)$ \\
\hline Small effect & $28(8.0)$ \\
\hline Moderate effect & $93(26.6)$ \\
\hline Large effect & $123(35.1)$ \\
\hline Extreme effect & $92(26.3)$ \\
\hline
\end{tabular}

*Pain measured on a 1 to 10 scale.

itive score on the PHQ-2 was a significant predictor, but a diagnosis of depression based on the chart review was not. The largest single contributor to the model was the SF-36 physical function scale. Poor function predicted a more severe effect on work. Analysis of interaction terms found important colinearity between current depressive symptoms and opioid use. Stratifying by presence of 
Table 3. Multivariate Model: Association With Score Measuring the Effect of Pain on Work

\begin{tabular}{|c|c|c|c|c|c|}
\hline & $\begin{array}{c}\text { All } \\
\text { Subjects } \\
\mathrm{N}=360\end{array}$ & $\begin{array}{c}\text { Depression } \\
\text { Screening } \\
\text { Negative } \\
\mathrm{N}=61\end{array}$ & $\begin{array}{c}\text { Depression } \\
\text { Screening } \\
\text { Positive } \\
\mathrm{N}=292\end{array}$ & $\begin{array}{c}\text { No } \\
\text { Opioid Use } \\
\mathrm{N}=150\end{array}$ & $\begin{array}{c}\text { Uses } \\
\text { Opioids } \\
\mathrm{N}=210\end{array}$ \\
\hline & \multicolumn{5}{|c|}{ Standardized $\beta$ Coefficients and Significance } \\
\hline Intercept & $3.09 \ddagger$ & $4.20 \neq$ & $2.81 \ddagger$ & $2.79 \ddagger$ & 3.64 \\
\hline Average pain level & $0.189 \neq$ & $\mathrm{x}$ & $0.168 \dagger$ & $0.148^{*}$ & $0.139^{*}$ \\
\hline Flare-up frequency, last 12 months & $0.108^{*}$ & $\mathrm{x}$ & $\mathrm{x}$ & $0.234 \dagger$ & $\mathrm{x}$ \\
\hline How often pain in last 30 days & $\mathrm{x}$ & $\mathrm{x}$ & $0.090^{*}$ & $\mathrm{x}$ & $0.123^{*}$ \\
\hline Effect of flare-up, last 12 months & $0.170 \ddagger$ & $0.379 \ddagger$ & $0.148 \dagger$ & $0.269 \ddagger$ & $\mathrm{x}$ \\
\hline $\begin{array}{l}\text { Positive depression screen } \\
\quad(\text { PHQ-2 score }>2)\end{array}$ & $0.131 \dagger$ & $\mathrm{x}$ & 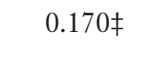 & $\mathrm{x}$ & $0.172 \dagger$ \\
\hline SF 36 Physical function score & $-0.382 \ddagger$ & $-0.579 \neq$ & $-0.355 \ddagger$ & $-0.348 \neq$ & $-0.460 \neq$ \\
\hline Adjusted $R^{2}$ & 0.535 & 0.685 & 0.452 & 0.609 & 0.398 \\
\hline
\end{tabular}

${ }^{*} P<.05$.

$\dagger P<.01$.

$\ddagger P<.001$.

PHQ-2, Patient Health Questionnaire.

depression yielded two regression models, with $\mathrm{N}=292$ for patients with depressive symptoms and $\mathrm{N}=61$ for patients with no depressive symptoms. The with-depression model had poorer overall correlation with the outcome variable (adjusted $R^{2}=0.452$ ) than the no-depression model (adjusted $R^{2}=0.685$ ). Additionally, fewer independent variables remained in the with-depression model. Only the pain flare-up effect and SF-36 physical function variables remained predictive of pain effect on work. Similarly, patients on opioids had poorer overall correlation $(\mathrm{N}=210$, adjusted $\left.R^{2}=0.398\right)$ than those not taking opioids $(\mathrm{N}=$ 150 , adjusted $R^{2}=0.609$ ).

\section{Discussion}

We found that patients with CLBP cared for by family physicians have significant depressive symptoms, their pain has a significant effect on their lives, and many are prescribed opioids. Pain flareups interfere with work function at least as much as average daily pain.

The contribution of flare-ups of CLBP on quality of life and disability have been recognized by others. ${ }^{31,32}$ A controlled trial of yoga versus other alternative treatments for CLBP recognized the importance of the yoga instructor helping patients manage pain flares. ${ }^{33}$ Our study adds further weight to the impact of pain flare-ups on patient functionality.
The SF-36 physical function scale measures selfreported tasks such as running, lifting, climbing stairs, kneeling, and bathing. Our finding of its association with effect of pain on work is consistent with one intervention study that found provocative tests of stepping and strength predicted return to work. ${ }^{21}$ Results of our regression analyses showed that particularly for patients who did not screen positive for depression, this measure of physical functioning had the largest association with work interference.

We did not administer the Fear-Avoidance Beliefs Questionnaire (FABQ). ${ }^{34}$ Previous studies found the FABQ to be an important psychosocial predictor of return to work and disability, ${ }^{34-40}$ and others have recommended its use. ${ }^{41}$ Fear avoidance has been found to be higher in patients with CLBP than acute pain, though distress was found to be a greater predictor of pain and disability. ${ }^{42}$ Results for fear avoidance are not consistent. ${ }^{43,44}$ A study of a brief, individualized program to reduce fear and increase activity levels found a reduction in patient fears, but no differences were observed in the percent unemployed or the percent receiving Worker's Compensation or disability benefits. ${ }^{45}$ A more recent systematic literature review of all prospective inception cohorts of patients with acute low back pain found little evidence to link such fear states with poor prognosis. These reviewers recommended that clinicians focus more on distress and depression. ${ }^{46}$ 
Our study was limited by its cross-sectional nature. This analysis could assess significant associations between pain, health, and the effects on work but was inadequate to determine cause and effect. For example, depression symptoms are significant predictors of the effect on work, but we cannot determine whether depression hinders one's ability to work, or the inability to work exacerbates depression. Further studies by this team, using longitudinal data, will shed light on those issues. It is also likely that the depressive symptoms we identified with the PHQ-2 overestimated the prevalence of major depression, because it is a more sensitive than specific diagnostic tool. ${ }^{47}$ Our study was also limited by using only one question to measure how CLBP interfered with work.

Our study also had potential selection biases. We only recruited subjects in the summer, which may limit who walks in the door and the types of conditions we saw, such as acute pain becoming chronic by the spring after falls in the winter. $\mathrm{Pa}-$ tients who were suspicious, drug-seeking, or particularly protective about their opioid medicines might be less likely to participate, though the frequent report of opioid use in our study makes these biases less likely. On the other hand, some CLBP patients might want to be especially cooperative to receive their prescriptions. Medical students may have only recruited the more "approachable" (and less antagonistic) patients; however, they were trained to invite all consecutive patients who met the screening criteria. Finally, patients with milder symptoms not seeking medications for CLBP on their visit that day may have been less likely to recognized as a potential study subject and not been approached by the medical students. This would lead to a study population with more severe CLBP than commonly seen in family physicians' practices.

Because this study was observational, we did not insist that family physicians screen and treat all their patients with CLBP for depression. We used the most sensitive cutoff score of the PHQ-2, which means there were false-positives for depression. ${ }^{47-48}$ Recognizing CLBP as a risk factor for depression means at least some patients could be identified and started on treatment. However, a review of studies of antidepressants for nonspecific low back pain found no difference compared with placebo for improved pain or depression. ${ }^{49}$

We also recommend that future studies of CLBP, including drug and device studies, include more than just overall pain scores as the outcome measure for pain. Previous research and our study have found flare-ups of pain to be associated with work status and disability. If one goal of CLBP treatment is to have people return to the employed workforce, then significant pain flare-ups must decrease both in frequency and severity, and patients must be psychologically better equipped to function despite the pain.

The researchers wish to thank all the dedicated medical and college students who helped us collect data each summer. We thank the participating physicians at each site for allowing our research team into their busy practices. We also appreciate the comments from the anonymous reviewers.

\section{References}

1. Rives PA, Douglass AB. Evaluation and treatment of low back pain in family practice. J Am Board Fam Pract 2004;17(Suppl):S23-31.

2. Martin BI, Deyo RA, Mirza SK, et al. Expenditures and health status among adults with back and neck problems. JAMA 2008;299:656-64.

3. van den Hoogen HJ, Koes BW, van Eijk JT, et al. On the course of low back pain in general practice: a one year follow up study. Ann Rheum Dis 1998;57:13-9.

4. Sinatra R. Opioid analgesics in primary care: challenges and new advances in the management of noncancer pain. J Am Board Fam Med 2006;19:165-77.

5. Gallagher RM, Rauh V, Haugh LD, et al. Determinants of return-to-work among low back pain patients. Pain 1989;39:55-67.

6. Coste J, Delecoeuillerie G, Cohen de Lara A, et al. Clinical course and prognostic factors in acute low back pain: an inception cohort study in primary care practice. BMJ 1994;308:577-80.

7. Gross DP, Battie MC, Cassidy JD. The prognostic value of functional capacity evaluation in patients with chronic low back pain: part 1: timely return to work. Spine 2004;29:914-19.

8. Hallner D, Hasenbring M. Classification of psychosocial risk factors (yellow flags) for the development of chronic low back and leg pain using artificial neural network. Neurosci Lett 2004;361:151-4.

9. Hasenbring M, Marienfeld G, Kuhlendahl D, Soyka D. Risk factors of chronicity in lumbar disc patients: a prospective investigation of biologic, psychologic, and social predictors of therapy outcome. Spine 1994;19:2759-65.

10. Kjellman G, Oberg B, Hensing G, Alexanderson K. A 12-year follow-up of subjects initially sicklisted with neck/shoulder or low back diagnoses. Physiother Res Int 2001;6:52-63.

11. Pincus T, Burton AK, Vogel S, Field AP. A systematic review of psychological factors as predictors of 
chronicity/disability in prospective cohorts of low back pain. Spine 2002;27:E109-20.

12. Soucy I, Truchon M, Cote D. Work-related factors contributing to chronic disability in low back pain. Work. 2006;26:313-26.

13. Valat JP, Goupille P, Rozenberg S, et al. Acute low back pain: predictive index of chronicity from a cohort of 2487 subjects: Spine Group of the Societe Francaise de Rhumatologie. Joint Bone Spine 2000;67:456-61.

14. van Poppel MN, Koes BW, Deville W, et al. Risk factors for back pain incidence in industry: a prospective study. Pain 1998;77:81-6.

15. Pincus T, Vlaeyen JW, Kendall NA, et al. Cognitive-behavioral therapy and psychosocial factors in low back pain: directions for the future. Spine 2002; 27:E133-8.

16. Haas M, Goldberg B, Aickin M, et al. A practicebased study of patients with acute and chronic low back pain attending primary care and chiropractic physicians: two-week to 48-month follow-up. J Manipulative Physiol Ther 2004;3:160-9.

17. van Tulder MW, Koes BW, Metsemakers JF, Bouter LM. Chronic low back pain in primary care: a prospective study on the management and course. Fam Pract 1998;2:126-32.

18. Deyo RA, Tsui-Wu YJ. Descriptive epidemiology of low-back pain and its related medical care in the United States. Spine 1987;12:264-8.

19. Hart LG, Deyo RA, Cherkin DC. Physician office visits for low back pain: frequency, clinical evaluation, and treatment patterns from a US national survey. Spine 1995;20:11-9.

20. Carragee EJ, Alamin TF, Miller JL, Carragee JM. Discographic, MRI and psychosocial determinants of low back pain disability and remission: a prospective study in subjects with benign persistent back pain. Spine J 2005;1:24-35.

21. Kool JP, Oesch PR, de Bie RA. Predictive tests for non-return to work in patients with chronic low back pain. Eur Spine J 2002;11:258-66.

22. Philips HC, Grant L. The evolution of chronic back pain problems: a longitudinal study. Behav Res Ther 1991;29:435-41.

23. Campbell J, Jones AS, Dienemann J, et al. Intimate partner violence and physical health consequences. Arch Intern Med 2002;162:1157-63.

24. Coker AL, Smith PH, Bethea L, et al. Physical health consequences of physical and psychological intimate partner violence. Arch Fam Med 2000;9: 451-7.

25. Humphreys J, Cooper BA, Miaskowski C. Differences in depression, posttraumatic stress disorder, and lifetime trauma exposure in formerly abused women with mild versus moderate to severe chronic pain. J Interpers Violence 2010;25:2316-38.

26. Stewart AL, Hays RD, Ware JE Jr. The MOS shortform general health survey: reliability and validity in a patient population. Med Care 1988;26:724-35.
27. Parkerson GR Jr, Michener JL, Wu LR, et al. Associations among family support, family stress, and personal functional health status. J Clin Epidemiol 1989;42:217-29.

28. Mori D, Lambert J, Niles B, et al. The BAI-PC as a Screen for Anxiety, Depression, and PTSD in Primary Care. J Clin Psychol Medical Settings 2003;10:187-92.

29. Kroenke K, Spitzer RL, Williams JB. The PHQ-9: validity of a brief depression severity measure. J Gen Intern Med 2001;16:606-13.

30. Straus M. Conflict Tactic Scales. In: Fredman N, Sherman R, editors. Handbook of Measurements for Marriage and Family Therapy. New York, NY: Bruner/Mazel Publishers; 1987.

31. Mason VL, Skevington SM, Osborn M. Development of a pain and discomfort module for use with the WHOQOL-100. Qual Life Res 2004;13:1139-52.

32. McGorry RW, Webster BS, Snook SH, Hsiang SM. The relation between pain intensity, disability, and the episodic nature of chronic and recurrent low back pain. Spine 2000;25:834-41.

33. Sherman KJ, Cherkin DC, Erro J, et al. Comparing yoga, exercise, and a self-care book for chronic low back pain: a randomized, controlled trial. Ann Intern Med 2005;143:849-56.

34. Waddell G, Newton M, Henderson I, et al. A FearAvoidance Beliefs Questionnaire (FABQ) and the role of fear-avoidance beliefs in chronic low back pain and disability. Pain 1993;52:157-68.

35. Grotle M, Vollestad NK, Veierod MB, Brox JI. Fear-avoidance beliefs and distress in relation to disability in acute and chronic low back pain. Pain 2004;112:343-52.

36. Woby SR, Watson PJ, Roach NK, Urmston M. Adjustment to chronic low back pain: the relative influence of fear-avoidance beliefs, catastrophizing, and appraisals of control. Behav Res Ther 2004;42:761-74.

37. Woby SR, Watson PJ, Roach NK, Urmston M. Are changes in fear-avoidance beliefs, catastrophizing, and appraisals of control, predictive of changes in chronic low back pain and disability? Eur J Pain 2004;8:201-10.

38. Crombez G, Vlaeyen JW, Heuts PH, Lysens R. Pain-related fear is more disabling than pain itself: evidence on the role of pain-related fear in chronic back pain disability. Pain 1999;80:329-39.

39. Denison E, Asenlof P, Lindberg P. Self-efficacy, fear avoidance, and pain intensity as predictors of disability in subacute and chronic musculoskeletal pain patients in primary health care. Pain 2004; 111:245-52.

40. Picavet HS, Vlaeyen JW, Schouten JS. Pain catastrophizing and kinesiophobia: predictors of chronic low back pain. Am J Epidemiol 2002;156:1028-34.

41. Staerkle R, Mannion AF, Elfering A, et al. Longitudinal validation of the fear-avoidance beliefs questionnaire (FABQ) in a Swiss-German sample of low back pain patients. Eur Spine J 2004;13:332-40. 
42. Grotle M, Vollestad NK, Brox JI. Clinical course and impact of fear-avoidance beliefs in low back pain: prospective cohort study of acute and chronic low back pain: II. Spine 2006;31:1038-46.

43. Sieben JM, Portegijs PJ, Vlaeyen JW, Knottnerus JA. Pain-related fear at the start of a new low back pain episode. Eur J Pain 2005;9:635-41.

44. Sieben JM, Vlaeyen JW, Portegijs PJ, et al. A longitudinal study on the predictive validity of the fearavoidance model in low back pain. Pain 2005;117: 162-70.

45. Von Korff M, Balderson BH, Saunders K, et al. A trial of an activating intervention for chronic back pain in primary care and physical therapy settings. Pain 2005; 113:323-30.
46. Pincus T, Vogel S, Burton AK, et al. Fear avoidance and prognosis in back pain: a systematic review and synthesis of current evidence. Arthritis Rheum 2006; 54:3999-4010.

47. Arroll B, Goodyear-Smith F, Crengle S, et al. Validation of PHQ-2 and PHQ-9 to screen for major depression in the primary care population. Ann Fam Med 2010;8:348-53.

48. Whooley MA, Avins AL, Miranda J, Browner WS. Casefinding instruments for depression: two questions are as good as many. J Gen Intern Med 1997;12:439-45.

49. Urquhart DM, Hoving JL, Assendelft WW, et al. Antidepressants for non-specific low back pain. Cochrane Database Syst Rev 2008;1:CD001703. 